\title{
Mouse vanin-1 is cytoprotective for islet beta cells and regulates the development of type 1 diabetes
}

\author{
C. Roisin-Bouffay $\cdot$ R. Castellano $\cdot$ R. Valéro • \\ L. Chasson $\cdot$ F. Galland $\cdot$ P. Naquet
}

Received: 6 February 2008 / Accepted: 30 March 2008 / Published online: 8 May 2008

(C) Springer-Verlag 2008

\begin{abstract}
Aims/hypothesis Islet cell death is a key initiating and perpetuating event in type 1 diabetes and involves both immune-mediated and endogenous mechanisms. The epithelial pantetheinase vanin-1 is proinflammatory and cytoprotective via cysteamine release in some tissues. We investigated the impact of a vanin-1 deficiency on islet death and type 1 diabetes incidence.
\end{abstract}

Electronic supplementary material The online version of this article (doi:10.1007/s00125-008-1017-9) contains supplementary material, which is available to authorised users.

C. Roisin-Bouffay · R. Castellano · L. Chasson · F. Galland •

P. Naquet

Aix Marseille Université, Faculté des Sciences de Luminy,

Centre d'Immunologie de Marseille-Luminy,

Marseille, France

C. Roisin-Bouffay • R. Castellano • L. Chasson • F. Galland •

P. Naquet

INSERM U631,

Marseille, France

C. Roisin-Bouffay $\cdot$ R. Castellano $\cdot$ L. Chasson $\cdot$ F. Galland

P. Naquet

CNRS UMR6102,

Marseille, France

R. Valéro

Aix Marseille Université, Service de Nutrition,

Maladies Métaboliques et Endocrinologie, CHU Timone,

Marseille, France

P. Naquet $(\triangle)$

Centre d'Immunologie de Marseille-Luminy, Campus de Luminy,

Case 906 Cedex 9,

13288 Marseille, France

e-mail: fgpn@ciml.univ-mrs.fr
Methods Vanin-1-deficient mice were produced and tested in drug-induced and autoimmune diabetes models. The contribution of vanin-1 to islet survival versus immune responses was evaluated using lymphocyte transfer and islet culture experiments.

Results The vanin-1/cysteamine pathway contributes to the protection of islet beta cells from streptozotocin-induced death in vitro and in vivo. Furthermore, vanin-1-deficient NOD mice showed a significant aggravation of diabetes, which depended upon loss of vanin-1 expression by host tissues. This increased islet fragility was accompanied by greater $\mathrm{CD} 4+$ insulitis without impairment of regulatory cells. Addition of cystamine, the product of pantetheinase activity, protected islets in vitro and compensated for vanin1 deficiency in vivo.

Conclusions/interpretation This study unravels a major cytoprotective role of cysteamine for islet cells and suggests that modulation of pantetheinase activity may offer alternative strategies to maintain islet cell homeostasis.

Keywords Cystamine - Cytoprotection - Islet beta cells . Pantetheinase · Type 1 diabetes

$\begin{array}{ll}\text { Abbreviations } \\ \text { CY } & \text { cyclophosphamide } \\ \text { iNOS } & \text { inducible nitric oxide synthase } \\ \text { mAb } & \text { monoclonal antibody } \\ \text { IP10 } & \text { interferon gamma inducible protein-10 } \\ \text { MCP1 } & \text { monocyte chemoattractant protein-1 } \\ \text { MIP-2 } & \text { macrophage inflammatory protein- } 2 \\ \text { NF-KB } & \text { nuclear factor kappa B } \\ \text { PKC } & \text { protein kinase C } \\ \text { PPAR } & \text { peroxisome proliferator-activated receptor } \\ \text { STZ } & \text { streptozotocin } \\ \text { Tregs } & \text { regulatory T cells }\end{array}$




\section{Introduction}

Type 1 diabetes is an autoimmune disease leading to a $\mathrm{T}$ cell-mediated destruction of insulin-producing islet cells. Loss of tolerance towards islet cell antigens plays a decisive role in the appearance of the disease [1-4]. However, to date still poorly identified intrinsic and environmental factors such as diet or infections can increase immunemediated diabetogenic inflammation and islet cell death $[5,6]$. In the NOD mouse model, disease progression proceeds through two sequential checkpoints [7]. Checkpoint 1 refers to the early accumulation of lymphocytes around islets after 3 weeks of age; this peri-insulitis progresses towards overt insulitis. Transition to insulitis might involve the abrupt release of pancreatic autoantigens upon stress or major metabolic changes provoked by weaning. Checkpoint 2 comprises progression to islet cell destruction and diabetes. During the Th1-driven aggressive phase of the disease, islet cell death is provoked by a combined lymphocyte-dependent Fas-, perforin- or cytokine-mediated cytotoxicity [8, 9]. Proinflammatory cytokines such as IL-1, TNF and IFN $\gamma$ synergise to induce islet beta cell death $[10,11]$ or to prime for Fas-mediated lysis [12, 13], but taken independently, each molecule is dispensable for diabetes progression $[8,14$, 15]. These cytokines reflect the presence of activated myeloid cells, which contribute to lymphocyte retention [16, 17] and generate oxidative stress in islets thus aggravating diabetes. Several investigations suggest that islet cells are particularly sensitive to oxidative stress [18]. Furthermore administration or transgenic overexpression of antioxidants can prevent diabetes onset [19-21]. Thus, regulators of inflammation and oxidative stress can influence diabetes by acting at the level of islet or immune cells. However, the relative contribution of cytoprotective versus destructive factors is unclear.

Vanin-1 is a pantetheinase expressed at the extracellular membrane of several epithelial tissues in mouse and man. Vanin-1 acts by locally modifying epithelial cell response to stress via pantetheinase-mediated cysteamine production [22]. Cysteamine and its oxidised form cystamine is a small thiol-containing compound suspected to modulate intracellular enzymatic activities involved in stress response and/or inflammation. Vanin-1-deficient $\left(V 1^{-/-}\right)$mice have undetectable levels of tissue cysteamine and display an enhanced resistance to systemic oxidative stress and intestinal inflammation [23]. In gut, the licensing role of vanin-1 in inflammation is in part explained by the cysteaminemediated inhibition of glutathione synthesis [24] and peroxisome proliferator-activated receptor (PPAR) $\gamma$ 's antiinflammatory function [25]. Under acute stress, vanin-1 behaves as an epithelial sensor that modulates the threshold of tissue response to stress and immune reactivity. However, cysteamine function may not be limited to the control of inflammation. In various models of neurodegenerative diseases [26-28], cystamine attenuates the severity of lesions by an as yet unknown mechanism. Since cysteamine is ubiquitously expressed in epithelial tissues, it might be either proinflammatory or cytoprotective in diabetes. We directly tested this hypothesis in drug-induced and autoimmune forms of the disease. Our results show that the absence of vanin-1 leads to greater diabetes incidence in all experimental models. This aggravation is explained by the loss of cysteamine-mediated islet cytoprotection rather than via an impact on inflammation. Thus cysteamine plays a major role in islet cell homeostasis during diabetes progression.

\section{Methods}

Mice and reagents Mice were kept in a specific pathogenfree mouse facility and handled according to the rules of Decret number 87-848 of 19 October 1987. Animal experiments were performed according to the legal authorisation certificates delivered for the Centre d'Immunologie de Marseille Luminy (authorisation 007031) and for permanent staff members P. Naquet (authorisation 13-70) and F. Galland (authorisation 13-139). NOD mice (provided by L. Chatenoud, Necker Hospital, Paris, France) and $V 1^{-/-}$NOD mice were bred in our facility under specific pathogen-free conditions. $V 1^{-/}$BALB/c mice were backcrossed on the NOD genetic background for 14 generations and intercrossed to produce $V 1^{-/-}$NOD mice. Diabetes incidence was monitored weekly by measuring glycosuria using colorimetric strips (Roche Molecular Biochemicals, Meylan, France) and confirmed by testing glycaemia with a glucometer (Accu-chek Active; Roche Molecular Biochemicals). Cohorts of 20 to 30 age-matched female or male mice were followed for up to 50 weeks. For long-term administration, cystamine (120 mg/kg body weight; Sigma) was injected i.p. four times per week (every second day) from age 8 to 28 weeks in $V 1^{-/}$or control NOD mice. For cyclophosphamide (CY)-induced diabetes [29], $200 \mathrm{mg} / \mathrm{kg}$ CY (Sigma, Saint-Quentin Fallavier, France) was injected i.p. to 8-week-old male mice. A second injection of $200 \mathrm{mg} / \mathrm{kg}$ was given 14 days later to non-diabetic mice. In these experiments, cystamine was injected 2 days before $\mathrm{CY}$ and repeated daily for 10 days. For multi low dose streptozotocin (STZ) experiments [30], 9-week-old female $V 1^{--}$or control BALB/c mice were injected i.p. with $40 \mathrm{mg} / \mathrm{kg}$ of body weight of STZ extemporarily prepared in citrate buffer $0.1 \mathrm{~mol} / \mathrm{l}(\mathrm{pH} 4.5$ ) over five consecutive days and diabetes was monitored for 2 weeks after the last injection. For multi low dose STZ or CY experiments, glycosuria was checked daily and confirmed after two glycaemia evaluations over $14 \mathrm{mmol} / \mathrm{l}$. Caspase 3 activation was quantified $24 \mathrm{~h}$ after a single STZ administration. 
Immunohistochemistry Pancreases were fixed overnight at $4^{\circ} \mathrm{C}$ in $4 \%$ formalin (vol./vol.) and for 1 to 2 days in sucrose $20 \%\left(\mathrm{wt} / \mathrm{vol}\right.$.) at $4^{\circ} \mathrm{C}$, before embedding in Tissue Tek (OCT Compound, Sakura Finetek Europe, Zoeterwoude, the Netherlands). Haemopoietic cell infiltration and insulin expression were analysed on $5 \mu \mathrm{m}$ pancreatic cryosections using a combination of anti-CD45 FITC monoclonal antibody (mAb; BD Biosciences, Le Pont de Claix, France) and guinea pig anti-human insulin antibody (Linco Research, St Charles, MO, USA), revealed with a Texas-Red goat antiguinea pig antiserum (Jackson Immuno-Research Europe, Newmarket, UK). To quantify islet cell regeneration, BrdU ( $1 \mathrm{mg} / \mathrm{ml}$; Sigma) was added to drinking water of 9-week-old NOD and $V 1^{-/}$mice for 3 weeks. Pancreatic sections from BrdU-treated mice were labelled with a combination of anti-CD45 FITC mAb, To-pro3 iodide (Molecular Probes, Invitrogen, Cergy Pontoise, France) and biotinylated antiBrdU antibody (BD Biosciences) revealed by streptavidin, Alexa fluor 546 conjugate (Molecular Probes). On sections, insulitis was scored: 0 , normal islet; 1 , peri-insulitis or invasive infiltration of less than $25 \%$ of islet surface area; 2 , invasive infiltration of 25 to $50 \%$ of islet surface area; 3 invasive infiltration greater than $50 \%$ of islet surface area or small retracted islet [31]. Fifty to 60 islets were scored per pancreas. To quantify caspase-3 activation during islet cell death, pancreatic sections were labelled with an anticleaved caspase-3 mAb (Cell Signaling Technology, Danvers, MA, USA), revealed using Alexa Fluor 488 goat anti-rabbit antibody (Molecular Probes). Quantitative analysis of stained cells was performed using the Image $\mathrm{J}$ software. Around 20 to 30 islets were analysed per pancreas.

Lymphocyte adoptive transfer For diabetes induction, $1 \times$ $10^{7}-2 \times 10^{7}$ splenocytes from diabetic NOD or $V 1^{-/-}$NOD donors were injected intravenously into irradiated (6 Gy) 6week-old male recipient control or $V 1^{-/-}$NOD mice [32]. Diabetes was monitored as previously. Regulatory CD4+T cells were isolated from lymph nodes of 4-week-old NOD and $V 1^{-/-}$NOD mice using the CD4+CD25+Regulatory $\mathrm{T}$ cell Isolation Kit (Miltenyi Biotec SAS, Paris, France). Purified $2 \times 10^{5} \mathrm{CD} 4+\mathrm{CD} 25+\mathrm{T}$ cells were injected in 9week-old control and $\mathrm{VI}^{--}$recipient NOD mice 2 days after $\mathrm{CY}$ injection. Blood glucose concentration was followed daily for 14 days. A second CY injection was performed on day 14 to non-diabetic mice.

Analysis of infiltrating haemopoietic cells Pancreases removed from 6- to 12-week-old female mice were cut in pieces and digested with collagenase IV (Serlabo, Entraigues sur la Sorgue, France) at $0.2 \mathrm{mg} / \mathrm{ml}$ in RPMI, $20 \mathrm{mmol} / 1$ HEPES, $2 \%$ FCS (vol./vol.) for $30 \mathrm{~min}$. Infiltrating cells were recovered as single cell suspensions after filtration on cell strainer (70 $\mu \mathrm{m}$ nylon; BD Biosciences) and Ficoll purification. Cells were directly labelled with combinations of allophycocyanin (APC)-coupled anti-CD4, peridininchlorophyll-protein complex (Per-CP)-coupled anti-CD8, Per-CP-coupled anti-CD25 or anti-CD3, biotinylated antiB220 or anti-CD11c, and FITC-coupled anti-CD11b mAbs (BD Biosciences).

Islet isolation and culture Langerhans islets were isolated from pancreas by digestion with collagenase P $(1 \mathrm{mg} / \mathrm{ml})$ (Roche Molecular Biochemicals) at $37^{\circ} \mathrm{C}$ for $20 \mathrm{~min}$ and further separated using a density gradient (Histopaque1077; Sigma). Islets were handpicked and incubated in rich medium supplemented with 10\% FCS (vol./vol.) and antibiotics. Islets (100-200) were cultured overnight in RPMI medium containing $10 \%$ bovine serum albumin (vol./vol.), 5\% penicillin-streptomycin (vol./vol.) before transplantation and in vitro studies. Islets were dispersed into single cell suspensions with $0.2 \%$ trypsin (wt/vol.; Gibco, Invitrogen), $10 \mathrm{mmol} / \mathrm{l}$ EDTA in Hanks' buffered salt solution. Islets were used directly after trypsin dissociation to extract RNA. For cytokine stimulation, islets were incubated overnight in CMRL (Connaught Medical Research Laboratories)-1066 medium (Invitrogen) with $10 \%$ FCS (vol./vol.) and antibiotics and exposed for 4 to 5 days to IL-1 $\beta(10 \mathrm{ng} / \mathrm{ml}$; Sigma) and IFN- $\gamma(100 \mathrm{ng} /$ $\mathrm{ml}$; Abcys biologie, Paris, France). For STZ-induced apoptosis [33], islets were incubated for $20 \mathrm{~h}$ in medium containing $0.5 \mathrm{mmol} / 1 \mathrm{STZ}$ (Sigma) dissolved in $0.1 \mathrm{mmol} / 1$ citrate buffer ( $\mathrm{pH}$ 4.5). Cystamine was added to islet cultures at a final concentration of $100 \mu \mathrm{mol} / \mathrm{l}$.

Apoptosis assay Islets were cultured for 5 days with cytokines, then dispersed into a single-cell suspension with trypsin, followed by recovery in complete medium at $37^{\circ} \mathrm{C}$ for $30 \mathrm{~min}$. Cell suspensions were incubated overnight in the dark in a $50 \mu \mathrm{g} / \mathrm{ml}$ propidium iodide, $0.1 \%$ sodium citrate (wt/vol.) and $0.1 \%$ Triton X-100 (vol./vol.) solution at $4^{\circ} \mathrm{C}$. Nuclear fragmentation was analysed on a flow cytometer [34]. The level of induced apoptosis was determined by the formula: $100 \times(\%$ apoptotic cells with cytokine or STZ $-\%$ background apoptotic cells $) /(100-\%$ background apoptotic cells).

Cytokine antibody array Mouse cytokine antibody arrays were incubated overnight at $4^{\circ} \mathrm{C}$ with $500 \mu \mathrm{g}$ of total CY-treated pancreatic lysates according to the manufacturer's instructions (RayBiotech, Norcross, GA, USA) and quantified using a chemiluminescence imaging system (Intelligent Dark Box II; FUJIFILM, Saint-Quentin en Yvelines, France). Relative cytokine expression levels were determined using the Multi Gauge V2.3 software (FUJIFILM). Internal controls included in the array were used to normalise the results from different membranes. 
Experiments were performed in duplicate for each mouse genotype.

Real-time quantitative PCR Reverse transcription was performed using a reverse transcription kit (QuantiTect; Qiagen, Courtaboeuf, France). Expression of mouse vanin-1, insulin, macrophage inflammatory protein-2 (MIP-2), monocyte chemoattractant protein-1 (MCP-1), interferon gamma inducible protein-10 (IP10), Fas, FasL, inducible nitric oxide synthase (iNOS), IL-12p35, IFN $\gamma$ and IL-1 $\beta$ was measured by the real-time quantitative RT-PCR method using SYBR green Master Mix (Applied Biosystems, Foster City, CA, USA) and the Mx3000P Real-Time PCR system (Stratagene, La Jolla, CA, USA). Relative mRNA levels were determined by the comparative threshold cycle (2- $\Delta \Delta C T$ ) method [35]. The expression of all mRNAs was normalised to that of actin mRNA. Sequences of all primers used in this study are listed in Electronic supplementary material (ESM) Table 1.

Statistical analysis Kaplan-Meier graphs showing diabetes incidence were analysed using the log rank test. For in vitro assays, Student's $t$, ANOVA or Kruskal-Wallis tests were used as indicated.

a

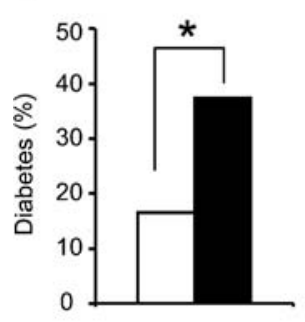

b

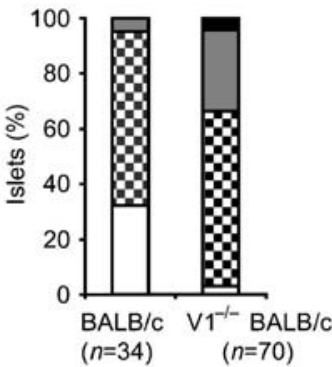

d

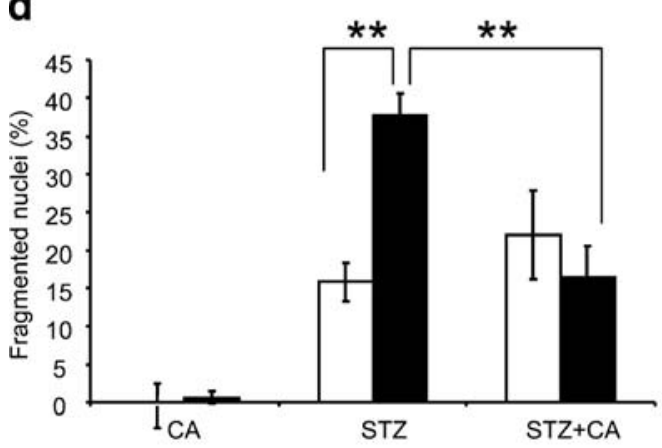

\section{Results}

Vanin-1 regulates islet sensitivity to cell death induction Islet cell death is a main determinant of diabetes progression and can be the consequence of various stresses [9]. We first checked whether vanin-1 deficiency would affect glucose metabolism. Both basal glucose levels, Glut2 (now known as Slc2a2) mRNA expression and intravenous glucose tolerance tests were assayed and found to be normal in $V 1^{-/}$mice (data not shown). Islet fragility was then explored by injecting in vivo STZ, a known inducer of islet cell death. Multi low dose STZ administration to $V 1^{-/-}$ $\mathrm{BALB} / \mathrm{c}$ mice provoked a twofold increase in diabetes incidence compared with control mice (log rank test: $p<$ 0.05 ) and was accompanied by a higher level of haemopoietic cell infiltration (Fig. $1 \mathrm{a}-\mathrm{c}$ ). This result was confirmed in vitro by culturing BALB/c islets in the presence of STZ. As shown in Fig. $1 \mathrm{~d}, V 1^{-/}$islets were twofold more susceptible to cell death induction than control islets and this effect was reversed by cystamine (unidirectional Kruskal-Wallis test: $p<0.01$ ). Caspase-3 is a main actor of STZ-induced cell death [33]. Thus we analysed by immunofluorescence the expression of active caspase- 3 in

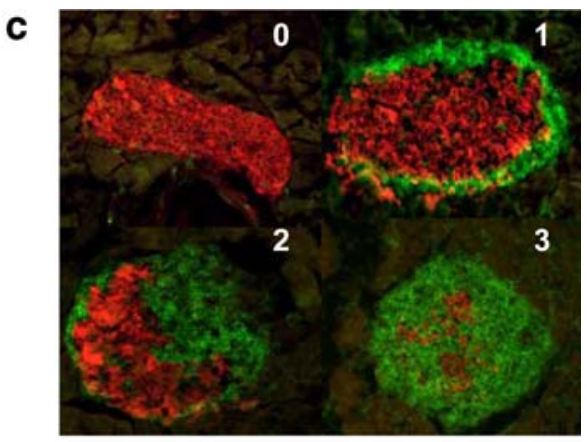

e

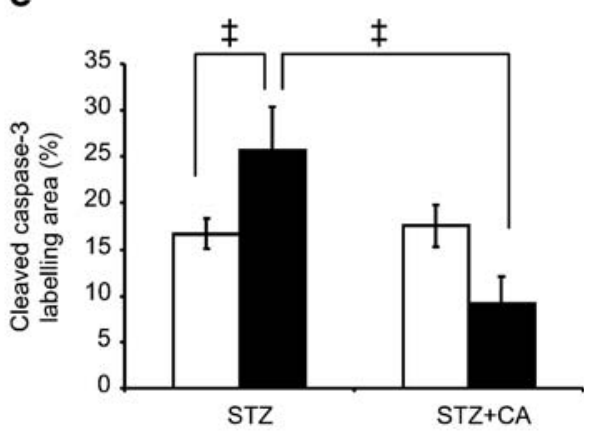

mice were incubated for $20 \mathrm{~h}$ with $0.5 \mathrm{mmol} / 1 \mathrm{STZ}$ and/or cystamine (CA) $100 \mu \mathrm{mol} / 1$ and cystamine alone; apoptotic cells were quantified as previously described (mean and SD from five independent experiments). Statistical analysis was performed using unidirectional Kruskal-Wallis test; ${ }^{* *} p<0.01$. e Quantification by immunofluorescence of activated caspase-3 in islets from mice treated with STZ $(50 \mathrm{mg} / \mathrm{kg})$ with or without cystamine $(120 \mathrm{mg} / \mathrm{kg})$. Statistical analysis

was by two-way (genotype/treatment) ANOVA; ${ }^{\ddagger} p<1 \times 10^{-5}$
Fig. 1 Islet cell survival in $\mathrm{VI}^{--}$mice. Multi low-dose STZ was injected i.p. to 9-week-old control (white column, $n=6$ ) and $V I$ (black column, $n=8$ ) BALB/c mice. a Diabetes was monitored; ${ }^{*} p<$ 0.05 by $\log$ rank test. b Insulitis was scored 13 days after the last STZ injection. Insulitis levels: 0 , white; 1 , chequered; 2 , grey; 3 , black. c This score was obtained by analysing sections with combined insulin (Texas Red) and CD45 (FITC) staining as indicated in the Methods section. d Control and $\mathrm{VI}^{-/-}$BALB/c islets from 8- to 20-week-old 
islets from STZ-treated control or $V 1^{-/-}$mice, pretreated or not with cystamine. Figure 1e shows an increased level of cleaved caspase- 3 in $V 1^{-/}$mice, with 25 versus $16 \%$ of islet area expressing active caspase-3 in $V 1^{-/}$or control mice respectively (two-way ANOVA test, $p<10^{-5}$ ). Cystamine administration significantly reduced the proportion of caspase-3-positive cells in $V 1^{-/}$mice ( $9 \%$ of islet area). These results document a statistically significant in vitro and in vivo cytoprotective effect on islets.

Increased insulitis and diabetes in $\mathrm{V1}^{-/-} \mathrm{NOD}$ mice We then tested whether this cytoprotective effect could modulate autoimmune diabetes. The vanin-1 deletion was introduced on the NOD background and vanin-1 expression was checked by quantitative RT-PCR on whole NOD pancreas and isolated islets. A similar level of expression was found in both exocrine and endocrine tissues in 3- and 8-week-old NOD mice (Fig. 2a). Then, diabetes incidence was monitored by measuring glycosuria in $V 1^{-/-}$and control NOD mice (Fig. 2b,c). In our NOD mouse colony, spontaneous

Fig. 2 Diabetes incidence in $V 1^{-/-}$NOD mice. a Relative vanin-1 expression in islets and exocrine pancreas from 3 - and 8-week-old control NOD (white bars) or $\mathrm{Vl}^{-/-}$NOD mice (black bars) normalised as indicated in Methods. b Diabetes incidence in female NOD $(n=119$; white symbols) and $V 1^{-/}$NOD ( $n=139$; black symbols) mice $\left({ }^{\dagger} p<0.0001\right)$ or (c) in male NOD $(n=24$; white symbols $)$ and $V 1^{-/-}$NOD $(n=28$; black symbols) mice $(* p<0.05)$. d Insulitis score in the pancreas of 6,8 and 12 week old, female $\mathrm{VI}^{-/-}$or control NOD mice. Scoring, as in Fig. 1. e Comparative analysis of islet regeneration between 9-week-old NOD and $\mathrm{VI}^{-/-}$ NOD male mice, estimated by BrdU incorporation. $* * p<0.01$ by Student's $t$ test. BrdU+ cells were counted among 3000-4000 CD45-negative islet cells in each experimental condition. $\mathbf{f}$ Corresponding insulitis scoring in the same mice. $\mathbf{g}$ Triple staining of islet sections using combined insulin (Texas Red), nuclei (To-pro3 iodide) and $\mathrm{BrdU}$ (FITC) staining $(\times 40)$ a

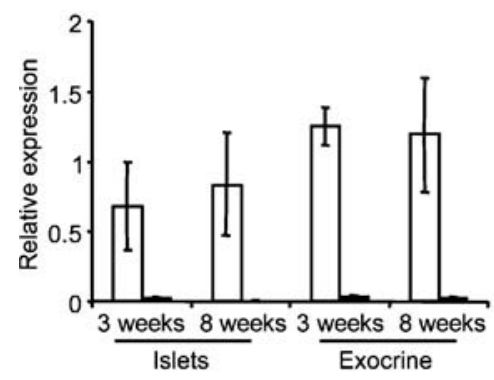

d
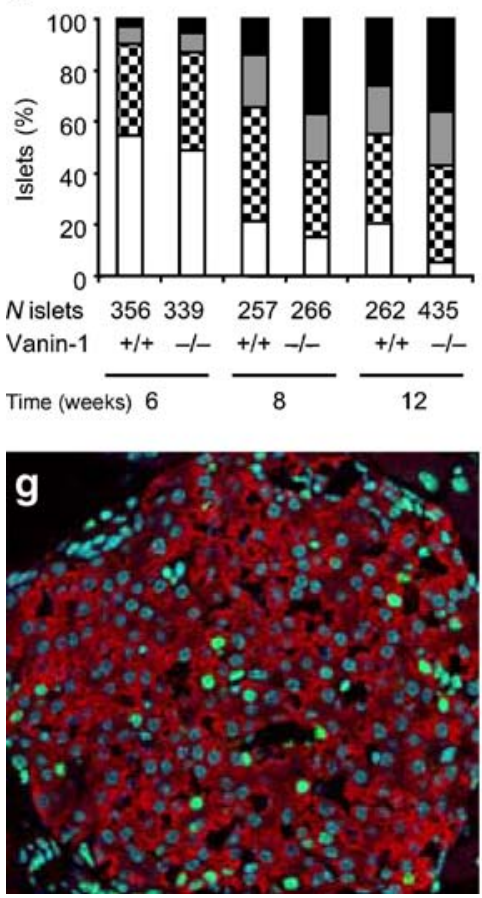

incidence was around $50 \%$ in 30 -week-old female mice, whereas male NOD mice did not develop diabetes. In contrast, $75 \% \mathrm{VI}^{-1-}$ female mice became diabetic within 25 weeks (log rank test: $\left.\chi^{2}=18.24 ; p<0.0001\right)$. Some $30 \%$ male mice also developed diabetes within 40 weeks (log rank test: $\left.\chi^{2}=4.26 ; p<0.05\right)$. We then compared the degree of insulitis at 6,8 and 12 weeks of age (Fig. 2d). A moderate insulitis is detectable in 6-week-old NOD mice and is associated with a destruction of $30 \%$ islets in 12-week-old mice in agreement with diabetes incidence. The degree of islet infiltration was more severe at all time points in $\mathrm{VI}^{-/}$mice and around $50 \%$ islets were destroyed at 8 weeks. Since islet survival depends upon equilibrium between destruction and regeneration, we quantified the amount of cycling islet cells following BrdU administration and compared it to the degree of infiltration. As shown in Fig. 2e-g, the percentage of BrdU-positive CD45-, insulin-producing epithelial cells was twice as high in $V 1^{-/}$animals in a context of higher infiltration $(p<0.01)$, suggesting that islet proliferation was not globally impaired in the mutant mice.

b

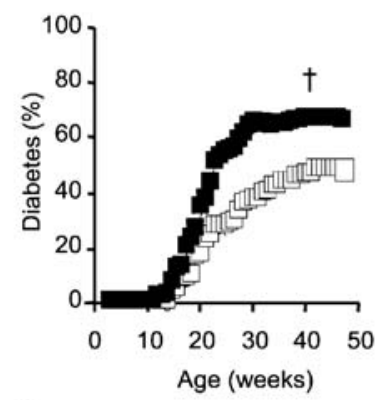

e

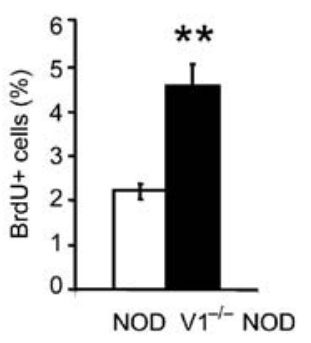

C

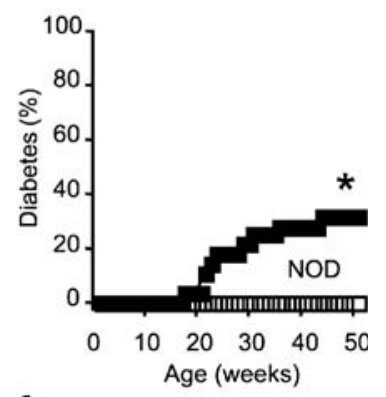

f

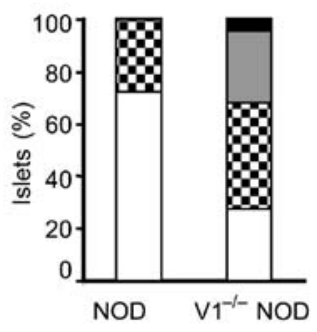




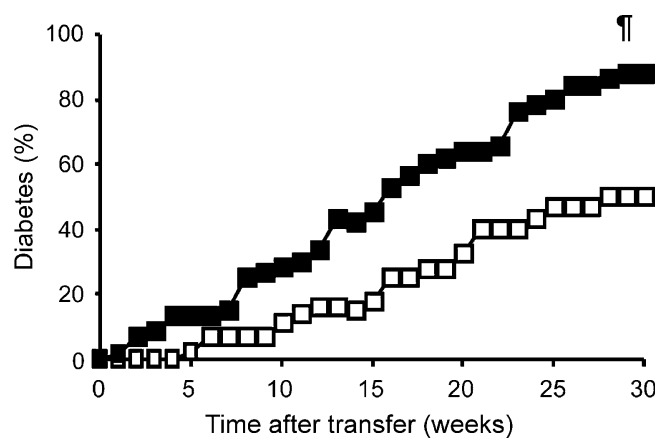

Fig. 3 Impact of host epithelial vanin-1 on diabetes. Diabetogenic lymphocytes $\left(10^{7}\right)$ from diabetic NOD mice were injected i.v. $24 \mathrm{~h}$ after irradiation (6 Gy) into 6-week-old male NOD (white symbols; $n=44$ ) or $V 1^{-/}$NOD (black symbols; $n=60$ ) irradiated recipients. Results represent the average of seven independent transfers $(p=0.0068)$

Vanin-1-dependent protection against diabetes is mediated by host tissue To check the contribution of host epithelial vanin-1, we used a transfer model in which total splenocytes from diabetic mice were injected into 6-week-old irradiated male NOD recipients. In this experimental setup, diabetes appears between 5 and 10 weeks after transfer in $50 \%$ NOD recipient mice (Fig. 3). The same population of NOD-derived diabetogenic splenocytes provokes a more rapid (2-3 vs $4-5$ weeks) and more penetrative $(90 \%$ vs $50 \%$ ) diabetes in $\mathrm{VI}^{-/}$NOD recipient mice (log rank test: $\chi^{2}=7.32 ; p=0.0068$ ). Thus $V 1^{-/-}$islets are more permissive to infiltration and/or effector cell activation. This could be explained by a differential response of host tissues to immune stress or to the impact of host tissue on the triggering of immune functions.

Vanin-1 deficiency is associated with enhanced Th1 responses The more aggressive insulitis observed in the spontaneous disease might be due to a cystamine-mediated skewing in immunocyte recruitment and/or activation. We performed a flow cytometric analysis of infiltrating cells in pancreas (Table 1). The total number of haemopoietic cells $\left(3.1 \times 10^{5} \pm 0.5\right.$ vs $\left.2.4 \times 10^{5} \pm 1.5\right)$ and the proportion of $\mathrm{T}$

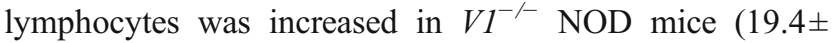
$3.9 \%$ vs $12.7 \pm 5.1 \%$ ). This augmentation mainly affected the CD4 and not the CD8 subset. Over 90\% CD4+ cells belonged to the effector/memory CD4+CD62L- and CD4+ CD25- subsets and contained 1 to $2 \%$ BrdU-positive cycling cells in both cohorts (data not shown). In contrast, the fraction of infiltrating macrophages was decreased in $V 1^{-/}$mice. Other haemopoietic cell subsets and levels of islet cell-specific auto-antibodies were comparable (data not shown). We then verified the pattern of chemokine secretion. A quantitative RT-PCR analysis on isolated islets detected transcripts of chemokines known to participate in islet cell infiltration such as MCP-1, MIP2 and IP10 (Fig. 4a), but did not document significant variations between control and vanin-1-deficient islets. A complementary analysis was performed using a chemokine/cytokine array in a CYinduced diabetes model, which allows samples to be analysed at a precise timing following CY-mediated triggering of diabetes. Results obtained from whole pancreatic extracts (Fig. 4b) revealed a modest decrease in levels of MIP1 $\gamma$, MIP2, MIP3 and regulated upon activation, normal $\mathrm{T}$ cells expressed and secreted (RANTES) in $\mathrm{VI}^{-/-}$mice, which might explain the reduction in macrophage infiltration. Concerning cytokines, quantitative RT-PCR analysis on isolated islets showed a significant increase $(p<0.05)$ in the expression of iNOS mainly (Fig. 4a) documenting a skewing towards M1 cell polarisation. Cytokine secretion by $\mathrm{T}$ lymphocytes was also checked by direct activation of enriched $\mathrm{CD} 45+$ cells from pancreases. Whereas IFN $\gamma$ secretion and FasL expression could be detected on CD3/ CD28-activated CD4+and CD8+T lymphocytes isolated from pancreatic infiltrates, no statistically significant difference was observed between control and $V 1^{-/}$NOD mice (data not shown). Since Th1-dependent proinflammatory cytokines provoke islet death, we cultured $V 1^{-/}$or control NOD islets in the presence of IL- $1 \beta$ and IFN $\gamma$. As shown in Fig. $4 \mathrm{c}$, both basal and cytokine-induced islet death was comparable, irrespective of the presence of the vanin-1 molecule. Thus, cystamine does not modulate cytokine-induced cell death pathways under these experimental conditions.

Vanin-1 deficiency is not associated with regulatory $T$ cell deficiency Progression towards the aggressive phase of diabetes requires an imbalance between effector cells and regulatory $\mathrm{T}$ cells (Tregs) $[1,36]$. Thus the increased CD4

Table 1 Distribution of infiltrating haemopoietic populations in islets from 12-week-old female NOD and $V 1^{-/-}$NOD mice

\begin{tabular}{|c|c|c|c|c|c|c|}
\hline \multirow[b]{2}{*}{ Islet source } & \multicolumn{6}{|c|}{ Infiltrating leucocytes } \\
\hline & B220+ & Mac-1+ & $\mathrm{CD} 11 \mathrm{c}+$ & $\mathrm{CD} 4+$ & CD8+ & $\mathrm{CD} 4+\mathrm{CD} 25+$ \\
\hline NOD & $29.5 \pm 10.5$ & $15.0 \pm 5.7$ & $2.4 \pm 0.3$ & $4.4 \pm 2.3$ & $6.4 \pm 0.9$ & $0.3 \pm 0.1$ \\
\hline$V 1^{-/-} \mathrm{NOD}$ & $30.0 \pm 3.60$ & $8.3 \pm 1.5$ & $2.8 \pm 0.1$ & $10.6 \pm 3.2$ & $8.2 \pm 2.7$ & $0.2 \pm 0.1$ \\
\hline
\end{tabular}

Values are the percentage of positive cells for the different leucocyte markers

Flow cytometric analysis of infiltrating leucocytes was performed by pooling three to four control or $V 1^{-/}$NOD mice per experimental point and analysing three to four independent experiments. SD was calculated between experimental points for each condition 
a
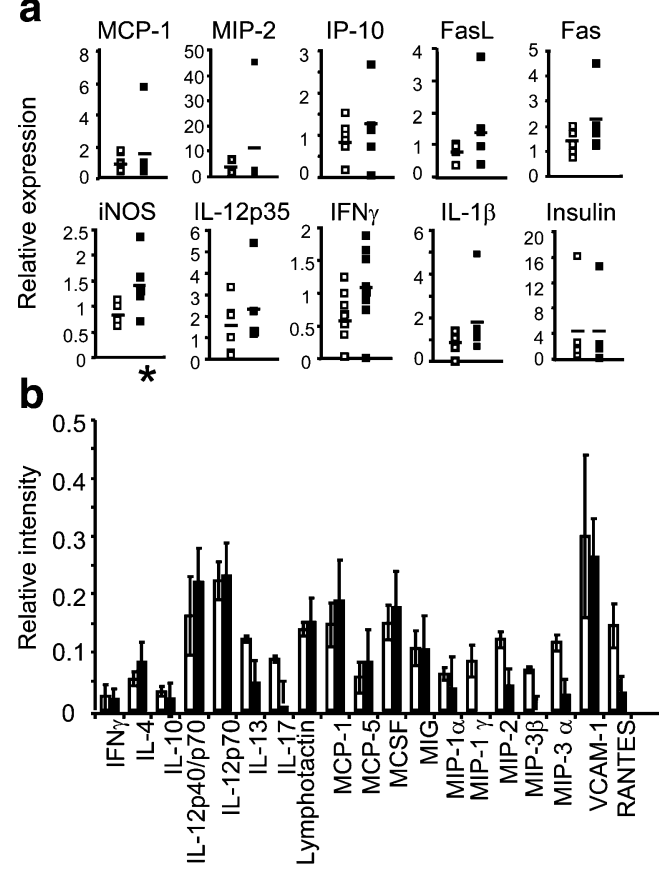

C

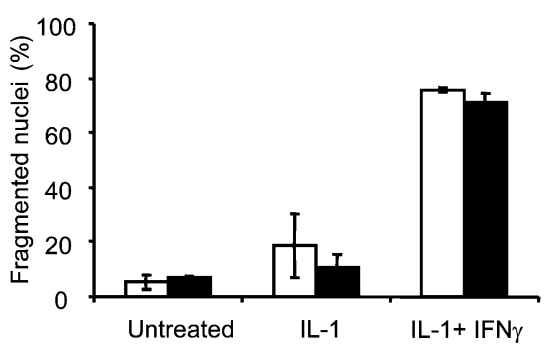

Fig. 4 Parameters of immune responses in islets. a Quantification by quantitative RT-PCR analysis of chemokine and cytokine relative expression levels in islets from 8-week-old female NOD (white symbols; $n=6$ ) and $V 1^{-/-}$NOD (black symbols; $n=5$ ) mice. For IFN $\gamma$ analysis, nine NOD and eight $V 1^{-/-}$NOD mice were tested. The bars represent the mean value for each quantification. Values were normalised by conferring a value of 1 for vanin-1 versus actin expression. ${ }^{*} p<0.05$. b Cytokine array performed on NOD (white bars) or $V 1^{--}$NOD (black bars) mice 10 days after $\mathrm{CY}$ injection. c NOD (white bars) and $V 1^{-/}$NOD (black bars) islets from 3-week-old mice were cultured in the presence of cytokines for 5 days and analysed by flow cytometry to quantify the proportion of apoptotic cells. Values are mean and SD from three independent experiments

cell infiltration in $V 1^{-/-}$NOD mice could be due to a reduced control by Tregs. To test this possibility, we developed a model of CY-induced diabetes in male NOD mice. CY acts by depleting proliferating lymphocytes including Tregs, leading to abrupt diabetes onset [37]. After two CY injections, 30 to $40 \%$ of 8 -week-old male NOD mice developed diabetes within 20 days (Fig. 5a). In contrast, 40 and $95 \%$ of $\mathrm{VI}^{-/-}$NOD mice developed diabetes after the first and second injection, respectively (log rank test: $\left.\chi^{2}=10.72 ; p=0.001\right)$. This result was correlated with an aggravated insulitis as observed in the natural disease (data not shown). This model system recapitulates the aggravating effect of vanin-1 deficiency. Both NOD and $V 1^{-/}$NOD mice display the same proportion of Tregs (between $0.5 \%$ and $2 \%$ ). We then comparatively tested their relative potency by injecting sorted $\mathrm{CD} 4+\mathrm{CD} 25+$ Tregs into $\mathrm{CY}$-treated $\mathrm{VI}^{-/-} \mathrm{NOD}$ mice. As shown in Fig. 5b, the intravenous administration of NOD or even more $V 1^{-/}$NOD Tregs significantly reduced diabetes onset (log rank test: $\chi^{2}=15.91 ; p=$ $0.0003)$. Thus the aggravated diabetic phenotype cannot be explained by a deficiency in Tregs in $V 1^{-/}$NOD mice.

Cystamine prevents $C Y$-induced diabetes and limits diabetes incidence in $\mathrm{VI}^{-/-}$mice These results suggest that cystamine administration might provide a novel strategy to limit islet cell death in ongoing diabetes. We thus injected cystamine in short-term CY-induced and spontaneous diabetes models. As shown in Fig. 6a, this treatment, given 2 days before and for the first 8 days following CY injection, provoked a drastic reduction in diabetes onset (log rank test: $\left.\chi^{2}=15.67 ; p<0.0001\right)$. However, once cystamine administration was interrupted and after a second $\mathrm{CY}$ injection, diabetes bounced back. We then treated $V 1^{-/}$ or control NOD mice during the pre-diabetic period (for 20 weeks). As shown in Fig. 6b, cystamine administration reduced diabetes incidence in $V 1^{--}$NOD mice, which slowly reappeared progressively after therapy ceased (data not shown). However, in this assay, the repetitive, long-

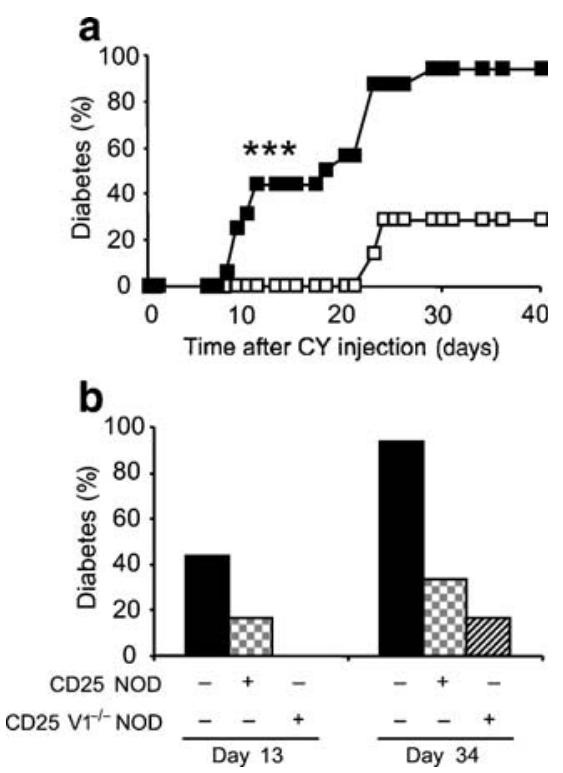

Fig. 5 Increased CY-induced diabetes in $V 1^{-/}$NOD male mice. a Cyclophosphamide $(200 \mathrm{mg} / \mathrm{kg})$ was injected i.p. on days 0 and 14 into 8-week-old male NOD (white symbols; $n=7$ ) and $V 1^{-/-}$NOD (black symbols; $n=16)$ mice $(* * * p=0.001)$. b Purified CD4+CD25+ Tregs from $\mathrm{VI}^{-/-}$NOD or NOD $\left(2 \times 10^{5}\right.$ cells $)$ donors were injected on day 2 after $\mathrm{CY}$ injection in $V 1^{-/-} \mathrm{NOD}$ recipient mice $(n=5)$. Diabetes incidence was scored on days 13 and 34 . The experiment was done twice and results represent one representative experiment $(p=0.0003)$ 
a

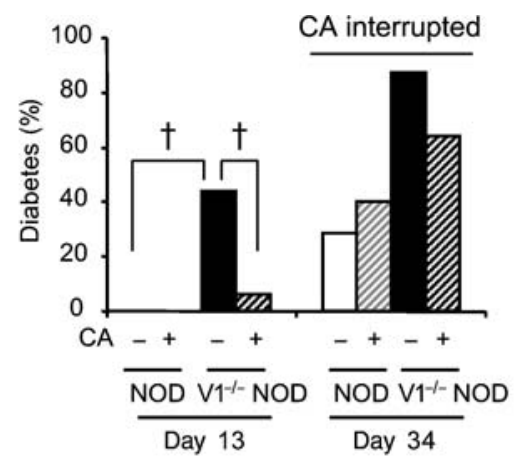

b

\begin{tabular}{|lccccc|}
\hline & Weeks & 10 & 15 & 20 & 25 \\
\hline $\mathrm{V} 1^{-/-} \mathrm{NOD}$ & $n=23$ & 0 & 3 & 9 & 12 \\
$\mathrm{~V}^{-/-} \mathrm{NOD}+\mathrm{CA}$ & $n=25$ & 0 & 3 & 5 & 7 \\
$\mathrm{NOD}$ & $n=8$ & 0 & 0 & 3 & 4 \\
$\mathrm{NOD}+\mathrm{CA}$ & $n=9$ & 0 & 0 & 1 & 2 \\
\hline
\end{tabular}

Fig. 6 Protective role of cystamine administration on diabetes incidence in $\mathrm{VI}^{-/-}$NOD mice. a CY-induced diabetes. Cystamine (CA) was given 2 days before and 8 days after a first $\mathrm{CY}$ injection in NOD $(n=5)$ or $V 1^{-/}$NOD mice $(n=17)$. Cystamine administration was interrupted after 10 days, followed by a second CY injection. Diabetes incidence was then followed for up to 50 days. Results represent average of two independent experiments. The log rank test was performed on these cohorts $\left({ }^{\dagger} p<0.0001\right)$. b Spontaneous diabetes: cystamine was administrated four times per week during 20 weeks and the number of diabetic mice is shown at 10, 15, 20 and 25 weeks in these cohorts $(p=0.08)$

term and stressful intra-peritoneal injections of PBS reduced the spontaneous incidence of diabetes in the colony from $75 \%$ to $52 \%$ thereby limiting the statistical significance of cystamine effect on the treated cohort $(p=0.08)$.

\section{Discussion}

Current understanding of the physiopathology of diabetes sees islet cell death as a key initiating and perpetuating event. The mechanisms involve developmental alterations, environmental insults, inflammatory and autoimmune processes [9]. Whereas immune and inflammatory effectors play a major role once the disease has started, the early death-inducing events might involve metabolic stress after weaning, alterations in prostaglandins homeostasis, which are responsible for endothelial dysfunction, or sensitivity of islet cells to oxidative stress $[18,38]$. Islet cell destruction provokes the release of pancreatic autoantigens and, in a susceptible background, autoimmunity. Mechanistically, the early insult and delayed immune-mediated damage provoke caspase-dependent apoptosis and cytokine-dependent necrosis of islet cells [11, 33]. An appropriate control of the disease should target early and late phases by inhibition of immune effectors [39] complemented by islet cytoprotection.
Vanin-1/pantetheinase provides tissue cysteamine, a proinflammatory molecule in gut acute stress [24, 25]. Consequently, vanin-1 deficiency might limit diabetes incidence in NOD mice. Alternatively, cysteamine has been shown to exert putative cytoprotective functions in neurodegenerative diseases. In this latter situation, its deficiency would further aggravate diabetes. Our results clearly indicated that in both drug-induced and autoimmune diabetes, disease incidence increased in the absence of cysteamine. In the NOD model, the aggravation was characterised by a more aggressive insulitis with islets enriched in CD4 Th1 lymphocytes. This enhanced Th1 response is not explained by a regulatory $\mathrm{T}$ cell deficiency. Efficient Th1 responses usually require powerful inflammatory signals, which were previously shown to be enhanced by vanin-1/cysteamine in gut infection or colitis models. In these models, inflammation is triggered by danger signals emanating from commensal or exogenous microbes. To evaluate islet susceptibility to vanin-1-mediated inflammation, we grafted them under the kidney capsule, a process known to generate proinflammatory danger signals [40]. These experiments indicated that irrespective of the vanin genotype of the grafted islets, inflammation was mainly determined by the genotype of the recipient kidney (data not shown). Indeed, in this experimental set up, inflammation was driven by the high levels of vanin-1 expression in kidney, which dominated the cytoprotective potential conferred by the low level of vanin-1 expression in islets. Thus cysteamine impact on disease may directly depend upon local tissue concentrations. In spontaneous diabetes, low-grade inflammation proceeds progressively in the absence of acute trauma; in this context, vanin-1 behaves as a cytoprotective rather than a proinflammatory molecule. The mechanisms of control of inflammation versus survival by cysteamine are poorly characterised. We previously demonstrated that cysteamine amplifies stress responses by altering redox metabolism and PPAR $\gamma$ activation, both involved in regulation of the nuclear factor kappa B (NF-kB) pathway [41, 42]. An islet cell-specific inhibition of this pathway abrogates cytokineor STZ-induced cell death [43]. In the absence of vanin-1, the diabetogenic effect of these treatments is unaltered or enhanced. Thus, under these experimental conditions, cysteamine rather behaves as a negative regulator of cell death. The question of whether this occurs through regulation of NF- $\mathrm{KB}$ activation remains to be answered, but this regulation is probably distinct from that involved in the enhancement of inflammation downstream of pattern recognition receptor-signalling in acute inflammatory models.

We currently favour the hypothesis that a basal cysteamine concentration limits stress-induced tissue destruction. Whereas it can protect from induced diabetes after a single CY injection, it cannot fully protect from STZ-induced or spontaneous autoimmune diabetes. In the latter model, 
aggravation of diabetes is strictly dependent upon host tissues and not linked to major alterations of immune responses. In vitro islet cultures mirror tissue resistance in short-term experiments. This suggests that islets are intrinsically modified in their ability to handle stress and that vanin-1/cysteamine regulate islet cell homeostasis. For a definitive molecular explanation, a better understanding of cysteamine action on intracellular pathways will be required. Several non-mutually exclusive possibilities can be envisaged. Few putative enzymatic cysteamine targets have been characterised: they include transglutaminases [44], caspase 3 and protein kinase C (PKC)E. STZ-induced cell death is dependent upon caspase 3 activation [33]. Interestingly, cystamine can partially inhibit caspase 3 in vitro [45] and this mechanism might contribute to its protective effect in Huntington's disease [26, 27]. Since it is not known whether cystamine can regulate the activity of other caspases, more extensive studies are required to establish this. Cysteamine also inhibits PKCE [46], which regulates signal transducer and activator of transcription1-dependent activation [47], a key effector arm in diabetes progression [48]. Irrespective of the mechanism involved, our results document a novel biological function of cysteamine through its ability to regulate islet beta cell survival, a mechanism which might also be involved in neuroprotection [28]. More generally, external events capable of altering cysteamine levels in islets could modulate diabetes progression, thus offering an alternative way of controlling the early islet cell destruction occurring in type 1 diabetes.

Acknowledgements This work was funded by a Juvenile Diabetes Research Foundation-INSERM-Fondation pour la Recherche Médicale grant and by the Eurothymaide project (LSHC-CT-2003-503410). C. Roisin-Bouffay and R. Castellano were supported by grants from Fondation pour la Recherche Médicale and Eurothymaide. The histological analyses were performed on the mouse functional genomics platform of the Marseille-Nice Genopole. We thank R. Guinamard for his helpful comments, and J. Imbert and P. Rihet for their help with statistical analysis.

Duality of interest The authors declare that there is no duality of interest associated with this manuscript.

\section{References}

1. You S, Belghith M, Cobbold S et al (2005) Autoimmune diabetes onset results from qualitative rather than quantitative agedependent changes in pathogenic T cells. Diabetes 54:1415-1422

2. Taubert R, Schwendemann J, Kyewski B (2007) Highly variable expression of tissue-restricted self-antigens in human thymus: implications for self-tolerance and autoimmunity. Eur J Immunol 37:838-848

3. Vafiadis P, Bennett ST, Todd JA et al (1997) Insulin expression in human thymus is modulated by INS VNTR alleles at the IDDM2 locus. Nat Genet 15:289-292
4. Kishimoto H, Sprent J (2001) A defect in central tolerance in NOD mice. Nat Immunol 2:1025-1031

5. Yoon JW, Jun HS (2006) Viruses cause type 1 diabetes in animals. Ann N Y Acad Sci 1079:138-146

6. Fujinami RS, von Herrath MG, Christen U, Whitton JL (2006) Molecular mimicry, bystander activation, or viral persistence: infections and autoimmune disease. Clin Microbiol Rev 19:80-94

7. Andre I, Gonzalez A, Wang B, Katz J, Benoist C, Mathis D (1996) Checkpoints in the progression of autoimmune disease: lessons from diabetes models. Proc Natl Acad Sci USA 93:2260-2263

8. Lee MS, Chang I, Kim S (2004) Death effectors of beta-cell apoptosis in type 1 diabetes. Mol Genet Metab 83:82-92

9. Mathis D, Vence L, Benoist C (2001) Beta-cell death during progression to diabetes. Nature 414:792-798

10. Nitta Y, Kawamoto S, Tashiro F et al (2001) IL-12 plays a pathologic role at the inflammatory loci in the development of diabetes in NOD mice. J Autoimmun 16:97-104

11. Steer SA, Scarim AL, Chambers KT, Corbett JA (2006) Interleukin-1 stimulates beta-cell necrosis and release of the immunological adjuvant HMGB1. PLoS Med 3:e17

12. Chervonsky AV, Wang Y, Wong FS et al (1997) The role of Fas in autoimmune diabetes. Cell 89:17-24

13. Amrani A, Verdaguer J, Thiessen S, Bou S, Santamaria P (2000) IL-1alpha, IL-1beta, and IFN-gamma mark beta cells for Fasdependent destruction by diabetogenic CD4(+) T lymphocytes. J Clin Invest 105:459-468

14. Apostolou I, Hao Z, Rajewsky K, von Boehmer H (2003) Effective destruction of Fas-deficient insulin-producing beta cells in type 1 diabetes. J Exp Med 198:1103-1106

15. Trembleau S, Penna G, Gregori S et al (1999) Pancreas-infiltrating Th1 cells and diabetes develop in IL-12-deficient nonobese diabetic mice. J Immunol 163:2960-2968

16. Nikolic T, Geutskens SB, van Rooijen N, Drexhage HA, Leenen PJ (2005) Dendritic cells and macrophages are essential for the retention of lymphocytes in (peri)-insulitis of the nonobese diabetic mouse: a phagocyte depletion study. Lab Invest 85:487-501

17. Martin AP, Alexander-Brett JM, Canasto-Chibuque C et al (2007) The chemokine binding protein $\mathrm{m} 3$ prevents diabetes induced by multiple low doses of streptozotocin. J Immunol 178:4623-4631

18. Haskins K, Bradley B, Powers K et al (2003) Oxidative stress in type 1 diabetes. Ann N Y Acad Sci 1005:43-54

19. Li X, Chen H, Epstein PN (2006) Metallothionein and catalase sensitize to diabetes in nonobese diabetic mice: reactive oxygen species may have a protective role in pancreatic $\beta$-cells. Diabetes 55:1592-1604

20. Bertera S, Crawford ML, Alexander AM et al (2003) Gene transfer of manganese superoxide dismutase extends islet graft function in a mouse model of autoimmune diabetes. Diabetes 52:387-393

21. Hotta M, Tashiro F, Ikegami H et al (1998) Pancreatic beta cellspecific expression of thioredoxin, an antioxidative and antiapoptotic protein, prevents autoimmune and streptozotocin-induced diabetes. J Exp Med 188:1445-1451

22. Pitari G, Malergue F, Martin F et al (2000) Pantetheinase activity of membrane-bound Vanin-1: lack of free cysteamine in tissues of Vanin-1 deficient mice. FEBS Lett 483:149-154

23. Berruyer C, Martin FM, Castellano R et al (2004) Vanin- $1^{-/}$mice exhibit a glutathione-mediated tissue resistance to oxidative stress. Mol Cell Biol 24:7214-7224

24. Martin F, Penet MF, Malergue F et al (2004) Vanin-1(-/-) mice show decreased NSAID- and schistosoma-induced intestinal inflammation associated with higher glutathione stores. J Clin Invest 113:591-597

25. Berruyer C, Pouyet L, Millet V et al (2006) Vanin-1 licenses inflammatory mediator production by gut epithelial cells and controls colitis by antagonizing peroxisome proliferator-activated receptor gamma activity. J Exp Med 203:2817-2827 
26. Karpuj MV, Becher MW, Springer JE et al (2002) Prolonged survival and decreased abnormal movements in transgenic model of Huntington disease, with administration of the transglutaminase inhibitor cystamine. Nat Med 8:143-149

27. Borrell-Pages M, Canals JM, Cordelieres FP et al (2006) Cystamine and cysteamine increase brain levels of BDNF in Huntington disease via HSJ1b and transglutaminase. J Clin Invest 116:1410-1424

28. Tremblay ME, Saint-Pierre M, Bourhis E, Levesque D, Rouillard C, Cicchetti F (2006) Neuroprotective effects of cystamine in aged Parkinsonian mice. Neurobiol Aging 27:862-870

29. Harada M, Makino S (1984) Promotion of spontaneous diabetes in non-obese diabetes-prone mice by cyclophosphamide. Diabetologia 27:604-606

30. McEvoy RC, Andersson J, Sandler S, Hellerstrom C (1984) Multiple low-dose streptozotocin-induced diabetes in the mouse. Evidence for stimulation of a cytotoxic cellular immune response against an insulin-producing beta cell line. J Clin Invest 74:715-722

31. Karges W, Hammond-McKibben D, Gaedigk R, Shibuya N, Cheung R, Dosch HM (1997) Loss of self-tolerance to ICA69 in nonobese diabetic mice. Diabetes 46:1548-1556

32. Bendelac A, Carnaud C, Boitard C, Bach JF (1987) Syngeneic transfer of autoimmune diabetes from diabetic NOD mice to healthy neonates. Requirement for both L3T4+ and Lyt-2+T cells. J Exp Med 166:823-832

33. Liadis N, Murakami K, Eweida M et al (2005) Caspase-3dependent beta-cell apoptosis in the initiation of autoimmune diabetes mellitus. Mol Cell Biol 25:3620-3629

34. Nicoletti I, Migliorati G, Pagliacci MC, Grignani F, Riccardi C (1991) A rapid and simple method for measuring thymocyte apoptosis by propidium iodide staining and flow cytometry. J Immunol Methods 139:271-279

35. Livak KJ, Schmittgen TD (2001) Analysis of relative gene expression data using real-time quantitative PCR and the 2(-Delta Delta $\mathrm{C}(\mathrm{T})$ ) method. Methods 25:402-408

36. Gregori S, Giarratana N, Smiroldo S, Adorini L (2003) Dynamics of pathogenic and suppressor $\mathrm{T}$ cells in autoimmune diabetes development. J Immunol 171:4040-4047
37. Brode S, Raine T, Zaccone P, Cooke A (2006) Cyclophosphamide-induced type-1 diabetes in the NOD mouse is associated with a reduction of $\mathrm{CD} 4+\mathrm{CD} 25+\mathrm{Foxp} 3+$ regulatory $\mathrm{T}$ cells. J Immunol 177:6603-6612

38. Nicolls MR, Haskins K, Flores SC (2007) Oxidant stress, immune dysregulation, and vascular function in type I diabetes. Antioxid Redox Signal 9:879-889

39. Shoda LK, Young DL, Ramanujan S et al (2005) A comprehensive review of interventions in the NOD mouse and implications for translation. Immunity 23:115-126

40. Matzinger P (2002) The danger model: a renewed sense of self. Science 296:301-305

41. Lehrke M, Lazar MA (2005) The many faces of PPARgamma. Cell 123:993-999

42. Pantano C, Reynaert NL, van der Vliet A, Janssen-Heininger YM (2006) Redox-sensitive kinases of the nuclear factor-kappaB signaling pathway. Antioxid Redox Signal 8:1791-1806

43. Eldor R, Yeffet A, Baum K et al (2006) Conditional and specific NF-kappaB blockade protects pancreatic beta cells from diabetogenic agents. Proc Natl Acad Sci U S A 103:5072-5077

44. Ientile R, Campisi A, Raciti G et al (2003) Cystamine inhibits transglutaminase and caspase-3 cleavage in glutamate-exposed astroglial cells. J Neurosci Res 74:52-59

45. Lesort M, Lee M, Tucholski J, Johnson GV (2003) Cystamine inhibits caspase activity. Implications for the treatment of polyglutamine disorders. J Biol Chem 278:3825-3830

46. Chu F, Koomen JM, Kobayashi R, O'Brian CA (2005) Identification of an inactivating cysteine switch in protein kinase Cepsilon, a rational target for the design of protein kinase Cepsiloninhibitory cancer therapeutics. Cancer Res 65:10478-10485

47. Ivaska J, Bosca L, Parker PJ (2003) PKCepsilon is a permissive link in integrin-dependent IFN-gamma signalling that facilitates JAK phosphorylation of STAT1. Nat Cell Biol 5:363-369

48. Suk K, Kim S, Kim YH et al (2001) IFN-gamma/TNF-alpha synergism as the final effector in autoimmune diabetes: a key role for STAT1/IFN regulatory factor-1 pathway in pancreatic beta cell death. J Immunol 166:4481-4489 